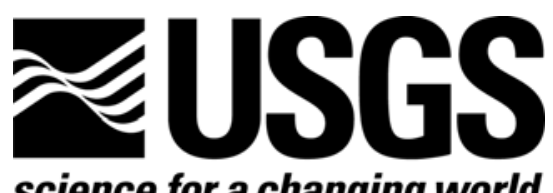

science for a changing world

\title{
Probabilistic Methodology for Estimation of Number and Economic Loss (Cost) of Future Landslides in the San Francisco Bay Region, California
}

Robert A. Crovelli ${ }^{1}$ and Jeffrey A. Coe ${ }^{2}$

${ }^{1}$ Retired, U.S. Geological Survey, Denver Federal Center, MS 939, Denver, CO 80225

${ }^{2}$ U.S. Geological Survey, Denver Federal Center, MS 966, Denver, CO 80225

Open-File Report 2008-1116

U.S. Department of the Interior

U.S. Geological Survey 


\section{U.S. Department of the Interior \\ DIRK KEMPTHORNE, Secretary}

\section{U.S. Geological Survey \\ Mark D. Myers, Director}

\section{U.S. Geological Survey, Reston, Virginia 2008}

For product and ordering information:

World Wide Web: http://www.usgs.gov/pubprod

Telephone: 1-888-ASK-USGS

For more information on the USGS - the Federal source for science about the Earth, its natural and living resources, natural hazards, and the environment:

World Wide Web: http://www.usgs.gov

Telephone: 1-888-ASK-USGS

Suggested citation:

Crovelli, R.A. and Coe, J.A., 2008, Probabilistic methodology for estimation of number and economic loss (cost) of future landslides in the San Francisco Bay Region, California: U.S. Geological Survey Open-File Report 2008-1116, 27 p.

Any use of trade, product, or firm names is for descriptive purposes only and does not imply endorsement by the U.S. Government.

Although this report is in the public domain, permission must be secured from the individual copyright owners to reproduce any copyrighted material contained within this report. 


\title{
Probabilistic Methodology for Estimation of Number and Economic Loss (Cost) of Future Landslides in the San Francisco Bay Region, California
}

\author{
Robert A. Crovelli and Jeffrey A. Coe
}

\begin{abstract}
The Probabilistic Landslide Assessment Cost Estimation System (PLACES) presented in this report estimates the number and economic loss (cost) of landslides during a specified future time in individual areas, and then calculates the sum of those estimates. The analytic probabilistic methodology is based upon conditional probability theory and laws of expectation and variance. The probabilistic methodology is expressed in the form of a Microsoft Excel computer spreadsheet program. Using historical records, the PLACES spreadsheet is used to estimate the number of future damaging landslides and total damage, as economic loss, from future landslides caused by rainstorms in 10 counties of the San Francisco Bay region in California. Estimates are made for any future 5-year period of time.

The estimated total number of future damaging landslides for the entire 10-county region during any future 5-year period of time is about 330. Santa Cruz County has the highest estimated number of damaging landslides (about 90), whereas Napa, San Francisco, and Solano Counties have the lowest estimated number of damaging landslides (5-6 each). Estimated direct costs from future damaging landslides for the entire 10-county region for any future 5-year period are about US \$76 million (year 2000 dollars). San Mateo County has the highest estimated costs ( $\$ 16.62$ million), and Solano County has the lowest estimated costs (about $\$ 0.90$ million). Estimated direct costs are also subdivided into public and private costs.
\end{abstract}

KEY WORDS: PLACES, probability, spreadsheet, landslide, cost, loss, risk, San Francisco Bay, California.

\section{INTRODUCTION}

Landslides occur nearly every year in the San Francisco Bay region of California. Most landslides occur during the late fall through early spring seasons, typically between December and April. During the fall through spring seasons of 1968-69, 1972-73, 198182, and 1997-98, landslides were widespread and caused extensive damage both to public and private property. Following these years, the U.S. Geological Survey (USGS) mapped locations of landslides that caused damage, and compiled the direct costs of damage to public and private property (Taylor and Brabb, 1972; Taylor and others, 1975; Creasy, 1988; Godt and others, 1999). The mapping and compilation were done for 10 counties in the region: Alameda, Contra Costa, Marin, Napa, San Francisco, Santa Clara, Santa Cruz, San Mateo, Solano, and Sonoma. Total numbers of, and costs from, damaging landslides in each of these counties are listed in table 1. 
The length of the historical record used in this report (referred to as "past time" in table 1) is 39 years (1968/69-2006/07) for all counties except Santa Cruz, which is 35 years because data were not collected in Santa Cruz County in 1968-69 and 1972-73. Even though 39 and 35 years were used as the length of record, during this timeframe, we only had data available for the fall through spring seasons of 1968-69, 1972-73, 1981-82, and 1997-98. Because of this fact, the historical record used in this report is incomplete and all estimates of future landslide numbers and costs must be considered minimum estimates. This statement is true for several reasons, including the following: (1) some years between 1968 and present (September 2007) have had landslides that caused damage (for examples, see Brown, 1988) that were not recorded by the USGS, (2) there were undoubtedly some landslides that caused damage during the years when records were kept (that is, 1968-69, 1972-73, 1981-82, and 1997-98) that were missed by the various USGS compilers, and (3) historical records of costs from landslides triggered by earthquakes were not included in the study. Additional limitations of our analysis are that (1) we do not take into account any future increases or decreases in precipitation due to changing climatic conditions; we assume that precipitation conditions in the future will be similar to those reflected by the historical record, and (2) we do not explicitly account for future patterns of growth in public and private development that may affect future numbers and costs of damaging landslides.

To analyze the historical cost data, we have used a newly developed Probabilistic Landslide Assessment Cost Estimation System (PLACES) to estimate the mean (or expected) number of future damaging landslides and the mean economic losses from the landslides. Along with mean estimates, PLACES calculates, for any specified future time, prediction interval (low, high) estimates at any specified prediction probability level (percent) and exceedance probabilities at any specified loss exceedance level (dollars).

PLACES significantly expands on probability methods for landslide data that were previously described by Crovelli (2000). An application of the methods described by Crovelli (2000) using historical landslide data from Seattle was described by Coe and others (2004). PLACES expands on these previous studies primarily through the addition of methods to partition and aggregate landslide costs. New features include the concept of landslide clusters and landslides per cluster, costs of damage to public and private property, aggregation of totals under various degrees of correlation, and the inclusion of the complete historical data set from the San Francisco Bay region. The historical record of landslide costs in the San Francisco Bay region, which is unique because of the internal consistency of the data and the longevity of the compilation effort, serves as an ideal data set for an application of PLACES.

PLACES uses probabilistic methodology for analysis of a particular set of landslide random variables. A random variable is a variable that has a probability distribution, along with a mean and a standard deviation. The PLACES probabilistic methodology involves the following random variables and their relationships, which form an outline of the probabilistic methodology section of this report: 
(1) Number of landslide clusters

(2) Recurrence interval of landslide clusters

(3) Number of landslides per landslide cluster

(4) Cost of landslides per landslide cluster

(5) Total number of landslides -

(5) is a function of (1) and (3).

(6) Total cost of landslides -

(6) is a function of (1) and (4).

(7) Fraction or percentage/100 (public and private)

(8) Fraction of total cost of landslides (public and private) -

(8) is a function of (6) and (7).

(9) Aggregation of total numbers of landslides -

(9) is a function of (5).

(10) Aggregation of total costs of landslides -

(10) is individually a function of (6) and then (8).

Application and discussion sections follow the detailed description of the probabilistic methodology.

\section{PROBABILISTIC METHODOLOGY}

PLACES was designed from probabilistic methodology to calculate estimates of the number and economic loss (cost) of landslides during a specified future time in individual areas, and then calculate the sum of those estimates. The analytic probabilistic methodology was developed by deriving the necessary mathematical equations based upon conditional probability theory and laws of expectation and variance. The derivations of the necessary equations are given in the following sections.

\section{Number of Landslide Clusters}

Landslide cluster: A group of one or more landslides that occurs within an individual water year.

Water year: The year-long period between July 1 and June 30 of the following year. 
Discrete-time probability model for occurrence of landslide clusters: Binomial process where there is a series of water years and within each water year a landslide cluster may or may not occur.

Random variable $N(t)$ : Number of landslide clusters that occur during a time period of $t$ water years in a particular area.

Range of $N(t):\{0,1, \ldots, t\}$

Assumptions: There are $t$ independent water years. Within each water year a landslide cluster may or may not occur. The probability of a landslide cluster in a water year, denoted by $p$, remains constant from water year to water year.

Probability distribution of $N(t)$ : Binomial distribution with parameters $t$ and $p$.

Parameter $t$ : Specified number of water years.

Parameter $p$ : Probability of a landslide cluster in a water year.

Probability mass function: $P\{N(t)=n\}=C(t, n) p^{n}(1-p)^{t-n}$

Mean or expected value of $N(t): E[N(t)]=t p$

Standard deviation of $N(t): S[N(t)]=[t p(1-p)]^{1 / 2}$

Exceedance probability: Probability of one or more clusters during a time period of $t$ water years.

Exceedance probability: $P\{N(t) \geq 1\}=1-(1-p)^{t}$

Estimator of parameter $p: \underline{P}=N\left(t^{*}\right) / t^{*}$ where $t^{*}$ denotes observed fixed time.

\section{Recurrence Interval of Landslide Clusters}

Random variable $R$ : Recurrence interval is the number of water years from one landslide cluster until the next cluster.

Range of $R:\{1,2, \ldots\}$

Assumptions: There is a series of independent water years after a landslide cluster occurs until the next cluster occurs. Within each water year a landslide cluster may or may not occur. The probability of a landslide cluster in a water year, denoted by $p$, remains constant from water year to water year. 
Probability distribution of $R$ : Geometric distribution with parameter $p$.

Parameter $p$ : Probability of a landslide cluster in a water year.

Probability mass function: $P\{R=r\}=p(1-p)^{r-1}$

Mean recurrence interval is the average time between landslide clusters.

Mean or expected value of $R: E[R]=1 / p$

Standard deviation of $R: S[R]=\left[(1-p) / p^{2}\right]^{1 / 2}$

Exceedance probability: Probability of a recurrence interval being greater than $r$ water years.

Exceedance probability: $P\{R>r\}=(1-p)^{r}$

Estimator of parameter $p: \underline{P}=N\left(t^{*}\right) / t^{*}$ where $t^{*}$ denotes observed fixed time.

\section{Number of Landslides per Landslide Cluster}

Random variable $L$ : Number of landslides per landslide cluster.

Range of $L:\{1,2, \ldots\}$

Mean or expected value of $L: E[L]$

Standard deviation of $L: S[L]$

Estimator of $E[L]$ : Sample mean $M_{L}$, based on $n$ observed landslide clusters.

$M_{L}=\frac{\sum_{i=1}^{n} L_{i}}{n}$

Estimator of $S[L]$ : Sample standard deviation $S_{L}$, based on $n$ observed landslide clusters.

$S_{L}^{2}=\frac{n \sum_{i=1}^{n} L_{i}^{2}-\left(\sum_{i=1}^{n} L_{i}\right)^{2}}{n(n-1)}$ 


\section{Cost of Landslides per Landslide Cluster}

Random variable $X$ : Cost of landslides per landslide cluster.

Range of $X:(0, \infty)$

Mean or expected value of $X: E[X]$

Standard deviation of $X: S[X]$

Estimator of $E[X]$ : Sample mean $M_{X}$, based on $n$ observed landslide clusters.

$M_{X}=\frac{\sum_{i=1}^{n} X_{i}}{n}$

Estimator of $S[X]$ : Sample standard deviation $S_{X}$, based on $n$ observed landslide clusters.

$S_{X}^{2}=\frac{n \sum_{i=1}^{n} X_{i}^{2}-\left(\sum_{i=1}^{n} X_{i}\right)^{2}}{n(n-1)}$

\section{Total Number of Landslides}

Random variable $M(t)$ : Total number of landslides from all of the landslide clusters during a time period of $t$ water years in a particular area.

$M(t)=\sum_{i=1}^{N(t)} L_{i}$

where random variable $L_{i}$ : Number of landslides from the $i$ th landslide cluster.

Range of $M(t):\{n, n+1, \ldots\}$

Assumptions: The $L_{i}(i=1,2, \ldots)$ are independent and identically distributed random variables which are also independent of $N(t)$.

The random variable $M(t)$ is equal to the sum of a random number $N(t)$ of random variables $L_{i}$. The mean and standard deviation of $M(t)$ can be derived from the theory of conditional probability and conditional expectation (Ross, 2000).

The derivation of the formula for the mean of $M(t)$ is given in Ross (2000, p. 103-104). 
Mean or expected value of $M(t): E[M(t)]=E[N(t)] E[L]$

The derivation of the formula for the standard deviation of $M(t)$ is given in Ross $(2000, \mathrm{p}$. 111-112).

Standard deviation of $M(t): S[M(t)]=\left\{E[N(t)](S[L])^{2}+(E[L])^{2}(S[N(t)])^{2}\right\}^{1 / 2}$

\section{Total Cost of Landslides}

Random variable $Y(t)$ : Total cost of landslides from all of the landslide clusters during a time period of $t$ water years in a particular area.

$Y(t)=\sum_{i=1}^{N(t)} X_{i}$

where random variable $X_{i}$ : Cost of landslides from the $i$ th landslide cluster.

Range of $Y(t):(0, \infty)$

Assumptions: The $X_{i}(i=1,2, \ldots)$ are independent and identically distributed random variables that are also independent of $N(t)$.

The random variable $Y(t)$ is equal to the sum of a random number $N(t)$ of random variables $X_{i}$. The mean and standard deviation of $Y(t)$ can be derived from the theory of conditional probability and conditional expectation (Ross, 2000).

The derivation of the formula for the mean of $Y(t)$ is given in Ross $(2000$, p. 103-104).

Mean or expected value of $Y(t): \mu_{\mathrm{Y}}=E[Y(t)]=E[N(t)] E[X]$

The derivation of the formula for the standard deviation of $Y(t)$ is given in Ross $(2000, \mathrm{p}$. 111-112).

Standard deviation of $Y(t): \sigma_{Y}=S[Y(t)]=\left\{E[N(t)](S[X])^{2}+(E[X])^{2}(S[N(t)])^{2}\right\}^{1 / 2}$

\section{Probability Distribution for Total Cost of Landslides}

Crovelli (1992) showed that the lognormal probability distribution is a good approximate distribution for the type of random variable $Y(t)$. Hence, the fractiles (fractiles are the complement of percentiles) of $Y(t)$ can be approximated by using the lognormal distribution.

$Y(t)$ is a sum of positive random variables and, therefore, is also a positive random variable. It is well known that sums of random variables tend to have a bell-shaped distribution and, by the Central Limit Theorem, approach the normal distribution. The 
lognormal distribution is a positive bell-shaped distribution. We also have the following statement from the updated classical reference book on continuous probability distributions (Johnson and others, 1994, p. 239): “The two-parameter [lognormal] distribution is, in at least one important respect, a more realistic representation of distributions of characters like weight, height, and density than is the normal distribution. These quantities cannot take negative values, but a normal distribution ascribes positive probability to such events, while the two-parameter lognormal distribution does not. Furthermore, by taking $\sigma$ small enough, it is possible to construct a lognormal distribution closely resembling any normal distribution. Hence, even if a normal distribution is felt to be really appropriate, it might be replaced by a suitable lognormal distribution."

As derived in Crovelli (1992), the characterizing parameters of the lognormal distribution, namely $\mu$ and $\sigma$, can be calculated from the mean $\mu_{Y}$ and standard deviation $\sigma_{Y}$ of a lognormal random variable $Y$.

The mean $\mu_{Y}$ and standard deviation $\sigma_{Y}$ of a lognormal random variable $Y$ with characterizing parameters $\mu$ and $\sigma$ are the following well-known formulas (Johnson and others, 1994, p. 212).

$$
\begin{aligned}
& \mu_{Y}=e^{\mu+\sigma^{2} / 2} \\
& \sigma_{Y}^{2}=e^{2 \mu+\sigma^{2}}\left(e^{\sigma^{2}}-1\right)
\end{aligned}
$$

Solving the two equations for the lognormal characterizing parameters $\mu$ and $\sigma$, we get

$$
\begin{aligned}
& \mu=\ln \left(\frac{\mu_{Y}^{2}}{\sqrt{\mu_{Y}^{2}+\sigma_{Y}^{2}}}\right) \\
& \sigma=\sqrt{\ln \left(\sigma_{Y}^{2} / \mu_{Y}^{2}+1\right)}
\end{aligned}
$$

The details of this derivation are given as Theorem 1 in the Appendix.

If one knows the lognormal characterizing parameters, the lognormal fractiles can be calculated from the formula

$F 100 \alpha=e^{\mu+z_{\alpha} \sigma} \quad 0 \leq \alpha \leq 1$

where $Z$ is a standard normal random variable and $P\left\{Z>z_{\alpha}\right\}=\alpha$.

For example, two fractiles of interest in this report are

$F 95=e^{\mu-1.645 \sigma} \quad$ and $\quad F 5=e^{\mu+1.645 \sigma}$ 
There is a $95 \%$ chance of exceeding $F 95$, and a $5 \%$ chance of exceeding $F 5$. Together, the low value of $F 95$ and the high value of $F 5$ form a range of values that is a $90 \%$ prediction interval for $Y(t)$, the total costs from landslides during a specified time (at a $90 \%$ prediction level).

The reverse problem would be to find the probability of exceeding a specified amount in economic loss due to landslides in a particular area during a specified time. That is, given $y_{\alpha}$, find $\alpha$ such that

$P\left\{Y(t)>y_{\alpha}\right\}=\alpha$

Normalizing

$$
z_{\alpha}=\frac{\ln y_{\alpha}-\mu}{\sigma}
$$

Now, from $z_{\alpha}$, find $\alpha$ such that $P\left\{Z>z_{\alpha}\right\}=\alpha$.

This probabilistic methodology would also apply in the case of the probability distribution for total number of landslides.

\section{Fraction of Total Cost of Landslides}

Public and private costs represent fractions of total cost of landslides.

Random variable $Z(t)$ : Fraction of total cost of landslides during a time period of $t$ water years in a particular area.

$Z(t)=F^{*} Y(t)$

where random variable $F$ : Fraction or percentage/100.

The random variable $Z(t)$ is equal to the product of a random fraction $F$ and the random variable $Y(t)$.

Range of $F:(0,1)$

Range of $Z(t):(0, \infty)$

Assumption: $F$ and $Y(t)$ are assumed to be independent.

Mean or expected value of $F: E[F]$ 
Standard deviation of $F: S[F]$

Estimator of $E[F]$ : Weighted mean $M_{F}$, based on $n$ observed landslide clusters with fractions $F_{i}$ and (weights) costs per cluster $X_{i}(i=1,2, \ldots, n)$.

$M_{F}=\frac{\sum_{i=1}^{n} F_{i} X_{i}}{\sum_{i=1}^{n} X_{i}}$

Estimator of $S[F]$ : Weighted standard deviation $S_{F}$, based on $n$ observed landslide clusters.

$$
S_{F}^{2}=\frac{\sum_{i=1}^{n} F_{i}^{2} X_{i}}{\sum_{i=1}^{n} X_{i}}-M_{F}^{2}
$$

The derivation of the following formulas for the mean and standard deviation of $Z(t)$ are given as Theorem 2 in the Appendix.

Mean or expected value of $Z(t): E[Z(t)]=E[F] E[Y(t)]$

Standard deviation of $Z(t)$ :

$$
S[Z(t)]=\left\{(S[F])^{2}(S[Y(t)])^{2}+(E[Y(t)])^{2}(S[F])^{2}+(E[F])^{2}(S[Y(t)])^{2}\right\}^{1 / 2}
$$

\section{Aggregation of Total Costs of Landslides}

Random variable $W(t)$ : Aggregation of total costs of landslides during a time period of $t$ water years in $k$ areas.

$W(t)=\sum_{i=1}^{k} Y_{i}(t)$

where random variable $Y_{i}(t)=Y_{i}$ : Total cost of landslides in the $i$ th area $(i=1,2, \ldots, k)$.

Range of $W(t):(0, \infty)$

The random variable $W(t)$ is equal to the sum of a fixed number $k$ of random variables $Y_{i}(t)$.

Mean or expected value of $W(t)$ : 
$E[W(t)]=\sum_{i=1}^{k} E\left[Y_{i}(t)\right]$

Variance of $W(t)$ :

$V[W(t)]=\sum_{i=1}^{k} V\left[Y_{i}\right]+2 \sum_{i<j} \operatorname{Cov}\left(Y_{i}, Y_{j}\right)$

where covariance of $Y_{i}$ and $Y_{j}$ :

$\operatorname{Cov}\left(Y_{i}, Y_{j}\right)=E\left[\left(Y_{i}-E\left[Y_{i}\right]\right)\left(Y_{j}-E\left[Y_{j}\right]\right)\right]$

Correlation coefficient of $Y_{i}$ and $Y_{j}$ :

$\rho_{i j}=\frac{\operatorname{Cov}\left(Y_{i}, Y_{j}\right)}{\sigma_{i} \sigma_{j}}$

where $\sigma_{i}=S\left[Y_{i}\right]$ : Standard deviation of $Y_{i}$

Number of distinct correlation coefficients $(i<j)$ :

$m=k(k-1) / 2$; for example, $k=10$, then $m=45$.

Variance of $W(t)$ :

$V[W(t)]=\sum_{i=1}^{k} \sigma_{i}^{2}+2 \sum_{i<j} \rho_{i j} \sigma_{i} \sigma_{j}$

Weighted-average correlation coefficient:

$\rho_{w a}=\frac{\sum_{i<j} \rho_{i j} \sigma_{i} \sigma_{j}}{\sum_{i<j} \sigma_{i} \sigma_{j}}$

If $\sigma_{i}=\sigma$ for all $i=1,2, \ldots, k$, then we get the average correlation coefficient:

$\rho_{w a}=\frac{\sum_{i<j} \rho_{i j}}{k(k-1) / 2}$

Variance of $W(t)$ : 
$V[W(t)]=\sum_{i=1}^{k} \sigma_{i}^{2}+2 \rho_{w a} \sum_{i<j} \sigma_{i} \sigma_{j}$

An algebraic relationship:

$$
\left(\sum_{i=1}^{k} \sigma_{i}\right)^{2}=\sum_{i=1}^{k} \sigma_{i}^{2}+2 \sum_{i<j} \sigma_{i} \sigma_{j}
$$

The final general case of variance of $W(t)$ :

$V[W(t)]=\sum_{i=1}^{k} \sigma_{i}^{2}+\rho_{w a}\left[\left(\sum_{i=1}^{k} \sigma_{i}\right)^{2}-\sum_{i=1}^{k} \sigma_{i}^{2}\right]$

Note that: $-1 \leq \rho_{w a} \leq 1$

The special cases are (a) uncorrelation or independence, (b) perfect positive correlation, and (c) perfect negative correlation.

(a) $\rho_{w a}=0 \Rightarrow$ uncorrelation or independence

(b) $\rho_{w a}=1 \Rightarrow$ perfect positive correlation

(c) $\rho_{w a}=-1 \Rightarrow$ perfect negative correlation

(a) $\quad V[W(t)]=\sum_{i=1}^{k} \sigma_{i}^{2}$

(b) $V[W(t)]=\sum_{i=1}^{k} \sigma_{i}^{2}+\left[\left(\sum_{i=1}^{k} \sigma_{i}\right)^{2}-\sum_{i=1}^{k} \sigma_{i}^{2}\right]=\left(\sum_{i=1}^{k} \sigma_{i}\right)^{2}$

(c) $V[W(t)]=\sum_{i=1}^{k} \sigma_{i}^{2}-\left[\left(\sum_{i=1}^{k} \sigma_{i}\right)^{2}-\sum_{i=1}^{k} \sigma_{i}^{2}\right]=2 \sum_{i=1}^{k} \sigma_{i}^{2}-\left(\sum_{i=1}^{k} \sigma_{i}\right)^{2}$

Standard deviation of $W(t)$ :

$S[W(t)]=\{V[W(t)]\}^{1 / 2}$

If $\sigma_{i}=\sigma$ for all $i=1,2, \ldots, k$, then 
(a) $V[W(t)]=\sum_{i=1}^{k} \sigma_{i}^{2}=\sum_{i=1}^{k} \sigma^{2}=k \sigma^{2}$

$S[W(t)]=\sqrt{k} \sigma$

(b) $V[W(t)]=\left(\sum_{i=1}^{k} \sigma_{i}\right)^{2}=\left(\sum_{i=1}^{k} \sigma\right)^{2}=(k \sigma)^{2}=k^{2} \sigma^{2}$

$S[W(t)]=k \sigma$

Ratios $: \quad R_{V}=\frac{k^{2} \sigma^{2}}{k \sigma^{2}}=k \quad \& \quad R_{S}=\frac{k \sigma}{\sqrt{k} \sigma}=\sqrt{k}$

For $k=25, \quad R_{V}=25 \quad \& \quad R_{S}=5$

For $k=100, \quad R_{V}=100 \quad \& \quad R_{S}=10$

For $k$ equal to 25 and 100, respectively, the variance of a sum of random variables with equal variances in the case of perfect positive correlation is 25 and 100 times greater than the variance of a sum of random variables with equal variances in the case of uncorrelation or independence.

For $k$ equal to 25 and 100, respectively, the standard deviation of a sum of random variables with equal standard deviations in the case of perfect positive correlation is 5 and 10 times greater than the standard deviation of a sum of random variables with equal standard deviations in the case of uncorrelation or independence.

Remarks concerning $\rho_{w a}$ :

1) Estimation of $\rho_{w a}$ directly can save considerable effort compared to the estimation of the $m$ individual $\rho_{i j}$, especially when $m$ is large.

2) Interpretation of $\rho_{w a}$ as a measure of the degree of weighted-average correlation of all of the random variables is helpful, especially when the value of $\rho_{w a}$ can be thought of as a decimal fraction (or percentage) lying somewhere between independence (0) and perfect positive correlation (1) inclusively.

3) When $\rho_{w a}=1$, the $V[W(t)]$ is larger than in the case when $\rho_{w a}=0$. On the other hand, when $\rho_{w a}=-1$, the $V[W(t)]$ is smaller than in the case when $\rho_{w a}=0$.

Also, we have:

In the case of perfect positive correlation, the means, standard deviations, and fractiles are additive.

This aggregation method is also used in the aggregation of total numbers of landslides where $M(t)$ would replace $Y(t)$. 


\section{SPREADSHEET AND APPLICATION}

The probabilistic methodology presented herein was used to construct a Microsoft Excel computer spreadsheet program. Using historical records, the PLACES spreadsheet was applied to estimate the number of future landslides, and total damage, as economic loss (cost), from future landslides caused by rainstorms in 10 counties of the San Francisco Bay region in California. Tables 1 and 2 contain summaries of historical cost data. These historical data were used in PLACES to estimate mean recurrence intervals and probabilities of future damaging landslide clusters (table 3); numbers of future landslides in a specified amount of time with confidence intervals and exceedance probabilities (table 4); and estimates of future total costs, and their aggregation, with prediction intervals and exceedance probabilities (table 5). The future specified time of 5 years used in the spreadsheet is a reasonable value selected for purely illustrative purposes. Table 6 contains historical cost data subdivided into public and private costs. PLACES estimates of public costs due to future landslides, and their aggregation, with prediction intervals and exceedance probabilities are given in table 7, whereas estimates of private costs due to future landslides are given in table 8. Recall that the historical record of landslides in the San Francisco Bay region is incomplete; therefore, all estimates of future numbers and costs (tables 3-5, 7-8) must be considered minimum estimates.

\section{DISCUSSION}

In the spreadsheet as it exists, the estimates of future total numbers and total costs of landslides in the San Francisco Bay region are based upon historical records from the region. When estimates of the future are based upon historical records, this could be referred to as a "historical" scenario. An assumption of the historical scenario is that the future will be similar to the past. In general, this assumption may or may not be acceptable in various applications. The problem is that everything in the physical world is continuously changing - nothing stays the same. Our information about the physical world is also continuously changing. If we have information that suggests the future will be different from the past in a certain "direction," for example, more landslides in the future than in the past, then we might want to modify the historical values of key parameters. That is, we might want to attempt some "what-if" scenarios by changing the historical values of certain key parameters in the PLACES model; for example, the probability of a landslide cluster might be increased. One of the most useful features of the PLACES spreadsheet is that we can modify the historical value of a key parameter and instantly see the effect on future estimates.

The probabilistic methodology and computer spreadsheet could be modified easily to become applicable to other types of hazards and even other types of disciplines. Therefore, there could be modifications of the PLACES system itself, besides modifications of values of parameters within the system. Two cases of modification of two different aspects of the system itself are given below. 


\section{Case 1: Continuous-Time Model}

It would be a very simple procedure to modify the PLACES system itself in the case where $N(t)$ has a Poisson distribution (continuous-time probability model) instead of a binomial distribution (discrete-time probability model), which would require that $R$ have an exponential distribution instead of a geometric distribution while the rest of the system would remain exactly the same.

\section{Number of Point Events}

Point event: An event that occurs at some time point in continuous time, where time is not discretized into one-year increments, as in the case of water years; for example, an earthquake.

Continuous-time probability model for occurrence of point events: Poisson process where there is a series of random point events in continuous time.

Random variable $N(t)$ : Number of point events that occur during time $t$ in a particular area.

Range of $N(t):\{0,1,2, \ldots\}$

Assumptions: The process has independent increments; that is, the numbers of point events that occur in disjoint time intervals are independent. The process has stationary increments; that is, the distribution of the number of point events that occur in any interval of time depends only on the length of the time interval.

Probability distribution of $N(t)$ : Poisson distribution with parameters $t$ and $\lambda$.

Parameter $t$ : Specified time interval.

Parameter $\lambda$ : Rate of occurrence of point events.

Probability mass function: $P\{N(t)=n\}=\mathrm{e}^{-\lambda t}(\lambda t)^{n} / n$ !

Mean or expected value of $N(t): E[N(t)]=\lambda t$

Standard deviation of $N(t): S[N(t)]=(\lambda t)^{1 / 2}$

Exceedance probability: Probability of one or more point events during time $t$.

Exceedance probability: $P\{N(t) \geq 1\}=1-\mathrm{e}^{-\lambda t}$

Estimator of parameter $\lambda: \underline{\lambda}=N\left(t^{*}\right) / t^{*}$ where $t^{*}$ denotes observed fixed time. 


\section{$\underline{\text { Recurrence Interval of Point Events }}$}

Random variable $R$ : Recurrence interval is the elapsed time between point events.

Range of $R:(0, \infty)$

Assumption: Probability model for occurrence of the point events is the Poisson process.

Probability distribution of $R$ : Exponential distribution with parameter $\lambda$.

Parameter $\lambda$ : Rate of occurrence of point events.

Probability density function: $f(r)=\lambda t \mathrm{e}^{-\lambda t r}$

Mean recurrence interval is the average time between point events.

Mean or expected value of $R: E[R]=1 / \lambda$

Standard deviation of $R: S[R]=1 / \lambda$

Exceedance probability: Probability of a recurrence interval being greater than time $r$.

Exceedance probability: $P\{R>r\}=\mathrm{e}^{-\lambda r}$

Estimator of parameter $\lambda: \underline{\lambda}=N\left(t^{*}\right) / t^{*}$ where $t^{*}$ denotes observed fixed time.

\section{Case 2: Cluster-of-One Model}

In the degenerate case where the cluster always consists of only one single event so that the "cluster" would now become the "event," we have

Random variable $L=1$

Mean or expected value of $L: E[L]=1$

Standard deviation of $L: S[L]=0$

Random variable $M(t)=N(t)$

Mean or expected value of $M(t): E[M(t)]=E[N(t)]$

Standard deviation of $M(t): S[M(t)]=S[N(t)]$

The rest of the system would remain exactly the same. 
This case would be appropriate for the following situations:

1. Modeling occurrence of seasonal floods (a series of single floods) by the binomial process (discrete-time probability model).

2. Modeling occurrence of earthquakes (a series of single earthquakes) by the Poisson process (continuous-time probability model).

\section{Reminder: Philosophy of Probability Models}

We include this section as a reminder for readers who apply the methodology (or use the results) presented in this report. It is very important to distinguish between hazardous processes themselves and our descriptions or models of these processes. At the scale of geologic and atmospheric hazards (for example, landslides, earthquakes, floods, tsunamis, volcanoes, and storms), nature is deterministic: every hazardous event has a cause. We cannot predict exactly when a hazardous event will occur because of the limitations to our knowledge of nature. A probability model is a mathematical model that incorporates our uncertainty. Probability models are used for purposes of description and prediction of physical processes in nature. Randomness is an assumption of probability models, not an inherent quality of natural processes. Hazards do not occur at random in nature, but they do occur at random in the models. In summary, hazardous processes are deterministic; but, because of our limitations when studying hazards, we resort to probability models that incorporate our uncertainty.

\section{SUMMARY}

This report presents probabilistic methodology (PLACES) that can be used to assess numbers and costs of future landslides based on historical data. The probabilistic methodology is expressed in the form of a Microsoft Excel computer spreadsheet program. Useful features of the methodology and spreadsheet are the following: (1) aggregation of totals under various degrees of correlation, (2) flexibility to modify parameter values within the system using the PLACES spreadsheet and instantly see the effect on future estimates, and (3) flexibility to modify the system itself using alternative probability models - two important cases are included in the report.

The PLACES spreadsheet is used to estimate the number of future damaging landslides, and total damage, as economic loss, from future landslides caused by rainstorms in 10 counties of the San Francisco Bay region in California. Estimates are made for any future 5-year period of time. The estimated total number of future damaging landslides for the entire 10 county region during any given 5 -year period of time is about 330 . Santa Cruz County has the highest estimated number of damaging landslides (about 90), whereas Napa, San Francisco, and Solano Counties have the lowest estimated number of damaging landslides (5-6 each). Estimated direct costs from future damaging landslides for the entire 10-county region for any future 5-year period are about US \$76 million (year 2000 dollars). San Mateo County has the highest estimated costs ( $\$ 16.62$ million), 
whereas Solano County has the lowest estimated costs (about \$0.90 million). Estimated direct costs are also subdivided into public and private costs.

\section{ACKNOWLEDGMENTS}

The authors wish to thank reviewers Dave Perkins and Brent Troutman for their helpful comments that improved the description of the probabilistic methodology.

\section{REFERENCES}

Brown, W.M., III, 1988, Historical setting of the storm: Perspectives on population, development, and damaging rainstorms in the San Francisco Bay region, in Ellen, S.D., and Wieczorek, G.F., eds., Landslides floods, and marine effects of the storm of January 3-5, 1982 in the San Francisco Bay region, California: U.S. Geological Survey Professional Paper 1434, p. 7-15.

Coe, J.A., Michael, J.A., Crovelli, R.A., and Savage, W.Z., Laprade, W.T., and Nashem, W.D., 2004, Probabilistic assessment of precipitation-triggered landslides using historical records of landslide occurrence, Seattle, Washington: Environmental and Engineering Geoscience, v. 10, p. 103-122.

Crovelli, R.A., 1992, Probabilistic methodology for estimation of undiscovered petroleum resources in play analysis of the United States: Nonrenewable Resources, v. 1, no. 2 , p. $153-162$.

Crovelli, R.A., 2000, Probability models for estimation of number and costs of landslides: U.S. Geological Survey Open-File Report 2000-249, 23 p., accessed March 7, 2008 at http://pubs.usgs.gov/of/2000/ofr-00-0249/

Godt, J.W. (editor), Arnal, C.H., Baum R.L., Brien, D.L., Coe, J.A., De Mouthe, J., Ellis, W.L., Graymer, R.W., Harp, E.L., Hillhouse, J.W., Houdre, N., Howell, D.G., Jayko, A.S., Lajoie, K.R., Morrissey, M.M., Ramsey, D.W., Savage, W.Z., Schuster, R.L, Wieczorek, G.F., and Wilson, R.C., 1999, Maps showing locations of damaging landslides caused by El Niño rainstorms, winter season 1997-98, San Francisco Bay region, California: U.S. Geological Survey Miscellaneous Field Studies Maps MF-2325A-J.

Johnson, N.L., Kotz, S., and Balakrishnan, N., 1994, Continuous univariate distributions: New York, John Wiley \& Sons, Inc., 2nd ed., 756 p.

Creasy, C.L., 1988, Landslide damage: A costly outcome of the storm, $\underline{\text { in }}$ Ellen, S.D., and Wieczorek, G.F., eds., Landslides, floods, and marine effects of the storm of January 3-5, 1982, in the San Francisco Bay region, California: U.S. Geological Survey Professional Paper 1434, p. 195-203. 
Ross, S.M., 2000, Introduction to probability models: San Diego, Harcourt, Academic Press, Inc., 7th ed., 693 p.

Taylor, F.A., and Brabb, E.E., 1972, Maps showing distribution and cost by counties of structurally damaging landslides in the San Francisco Bay region, California, winter of 1968-69: U.S. Geological Survey Miscellaneous Field Studies Map MF-327, scales $1: 500,000$ and $1: 1,000,000$.

Taylor, F.A., Nilsen, T.H., and Dean, R.M., 1975, Distribution and cost of landslides that have damaged manmade structures during the rainy season of 1972-1973 in the San Francisco Bay region, California: U.S. Geological Survey Miscellaneous Field Studies Map MF-679, scales 1:500,000 and 1:1,000,000.

U.S. Department of Labor, 1997, Bureau of Labor Statistics Handbook of Methods, variously paged.

\section{APPENDIX}

Calculation of the characterizing parameters of a lognormal distribution from its mean and standard deviation.

\section{Theorem 1}

If $Y$ has a lognormal distribution with characterizing parameters $\mu$ and $\sigma$, mean $\mu_{Y}$, and standard deviation $\sigma_{Y}$, then $\mu$ and $\sigma$ can be calculated from $\mu_{Y}$ and $\sigma_{Y}$ by the following formulas:

$$
\begin{aligned}
& \mu=\ln \left(\frac{\mu_{Y}^{2}}{\sqrt{\mu_{Y}^{2}+\sigma_{Y}^{2}}}\right) \\
& \sigma=\sqrt{\ln \left(\sigma_{Y}^{2} / \mu_{Y}^{2}+1\right)}
\end{aligned}
$$

\section{Proof}

The mean $\mu_{Y}$ and variance $\sigma_{Y}^{2}$ of a lognormal random variable $Y$ with characterizing parameters $\mu$ and $\sigma$ are the following well-known formulas (Johnson and others, 1994, p. 212).

$$
\mu_{Y}=e^{\mu+\sigma^{2} / 2}
$$


$\sigma_{Y}^{2}=e^{2 \mu+\sigma^{2}}\left(e^{\sigma^{2}}-1\right)$

We now solve these two equations for the lognormal characterizing parameters $\mu$ and $\sigma$.

Solving for $\sigma$

$$
\begin{aligned}
& \sigma_{Y}^{2}=e^{2 \mu+\sigma^{2}}\left(e^{\sigma^{2}}-1\right) \\
& =\left(e^{\mu+\sigma^{2} / 2}\right)^{2}\left(e^{\sigma^{2}}-1\right) \\
& =\mu_{Y}^{2}\left(e^{\sigma^{2}}-1\right) \\
& \frac{\sigma_{Y}^{2}}{\mu_{Y}^{2}}+1=e^{\sigma^{2}} \\
& \sigma^{2}=\ln \left(\frac{\sigma_{Y}^{2}}{\mu_{Y}^{2}}+1\right) \\
& \sigma=\sqrt{\ln \left(\frac{\sigma_{Y}^{2}}{\mu_{Y}^{2}}+1\right)}
\end{aligned}
$$

Solving for $\mu$

$$
\begin{aligned}
& \mu_{Y}=e^{\mu+\sigma^{2} / 2} \\
& \ln \mu_{Y}=\mu+\sigma^{2} / 2 \\
& \mu=\ln \mu_{Y}-\sigma^{2} / 2 \\
& =\ln \mu_{Y}-(1 / 2) \ln \left(\frac{\sigma_{Y}^{2}}{\mu_{Y}^{2}}+1\right) \\
& =\ln \mu_{Y}-\ln \sqrt{\frac{\mu_{Y}^{2}+\sigma_{Y}^{2}}{\mu_{Y}^{2}}} \\
& =\ln \left(\frac{\mu_{Y}}{\sqrt{\mu_{Y}^{2}+\sigma_{Y}^{2}} / \mu_{Y}}\right)
\end{aligned}
$$




$$
=\ln \left(\frac{\mu_{Y}^{2}}{\sqrt{\mu_{Y}^{2}+\sigma_{Y}^{2}}}\right)
$$

Mean and standard deviation of a product of two independent random variables

\section{Theorem 2}

If $X$ and $Y$ are independent random variables with means $E[X]$ and $E[Y]$ and standard deviations $S[X]$ and $S[Y]$, then

$E[X Y]=E[X] E[Y]$

$S[X Y]=\left\{(S[X])^{2}(S[Y])^{2}+(E[Y])^{2}(S[X])^{2}+(E[X])^{2}(S[Y])^{2}\right\}^{1 / 2}$

\section{Proof}

From Ross (2000, p. 50) we have the following theorem:

If $X$ and $Y$ are independent, then for any functions $g$ and $h$

$E[g(X) h(Y)]=E[g(X)] E[h(Y)]$

Therefore

$E[X Y]=E[X] E[Y]$

and

$E\left[X^{2} Y^{2}\right]=E\left[X^{2}\right] E\left[Y^{2}\right]$

From Ross (2000, p. 45) we have

Variance of $X: V[X]=E\left[X^{2}\right]-(E[X])^{2}$

Variance of $Y: V[Y]=E\left[Y^{2}\right]-(E[Y])^{2}$

We now consider

Variance of $X Y: V[X Y]=E\left[(X Y)^{2}\right]-(E[X Y])^{2}$

$=E\left[X^{2} Y^{2}\right]-(E[X] E[Y])^{2}$ 


$$
\begin{aligned}
& =E\left[X^{2}\right] E\left[Y^{2}\right]-(E[X])^{2}(E[Y])^{2} \\
& =E\left[X^{2}\right] E\left[Y^{2}\right]-(E[X])^{2} E\left[Y^{2}\right]-(E[Y])^{2} E\left[X^{2}\right]+(E[X])^{2}(E[Y])^{2} \\
& +(E[X])^{2} E\left[Y^{2}\right]+(E[Y])^{2} E\left[X^{2}\right]-(E[X])^{2}(E[Y])^{2}-(E[X])^{2}(E[Y])^{2} \\
& =\left\{E\left[X^{2}\right]-(E[X])^{2}\right\}\left\{E\left[Y^{2}\right]-(E[Y])^{2}\right\}+(E[X])^{2} E\left[Y^{2}\right] \\
& +(E[Y])^{2} E\left[X^{2}\right]-(E[X])^{2}(E[Y])^{2}-(E[X])^{2}(E[Y])^{2} \\
& =V[X] V[Y]+(E[Y])^{2}\left\{E\left[X^{2}\right]-(E[X])^{2}\right\}+(E[X])^{2}\left\{E\left[Y^{2}\right]-(E[Y])^{2}\right\} \\
& =V[X] V[Y]+(E[Y])^{2} V[X]+(E[X])^{2} V[Y] \\
& S[X Y]=\left\{(S[X])^{2}(S[Y])^{2}+(E[Y])^{2}(S[X])^{2}+(E[X])^{2}(S[Y])^{2}\right\}^{1 / 2}
\end{aligned}
$$




\section{TABLES}

Table 1. Summary of recorded numbers and costs of landslides in San Francisco Bay region of California. Sources of data for this table, and tables 2 and 6, are Taylor and Brabb (1972), Taylor and others (1975), Creasy (1988), and Godt and others (1999). Numbers of damaging landslides are taken from published text when available or, if written values are unavailable, from counted landslide locations on published maps. Costs were converted to August 2000 dollars using the Consumer Price Index (CPI) for shelter and guidelines described by the U.S. Department of Labor (1997). The percent change from each period to August 2000 was determined using the formula $\left(\left(\left(\mathrm{CPI}_{\text {August, }}\right.\right.\right.$ $\left.2000-\mathrm{CPI}_{\text {previous period }} / \mathrm{CPI}_{\text {previous period }} * 100\right)$. CPI values used were 30.5 for March 1969; 37.5 for March 1973; 97.0 for February 1982; and 222.9 for August 2000. Percent change values to August 2000 were 630.8\% from March 1969; 494.4\% from March 1973; $129.8 \%$ from February 1982; and $17.8 \%$ from February 1998. Although no data were recorded for Napa County in 1982, we assume that the number of landslides and costs were zero based on a statement by LaVopa Creasey (1988) that the county had "sustained relatively few landslides." Designations used in this table: no. of yrs., number of years; $10^{\wedge} 6 \$$, million dollars.

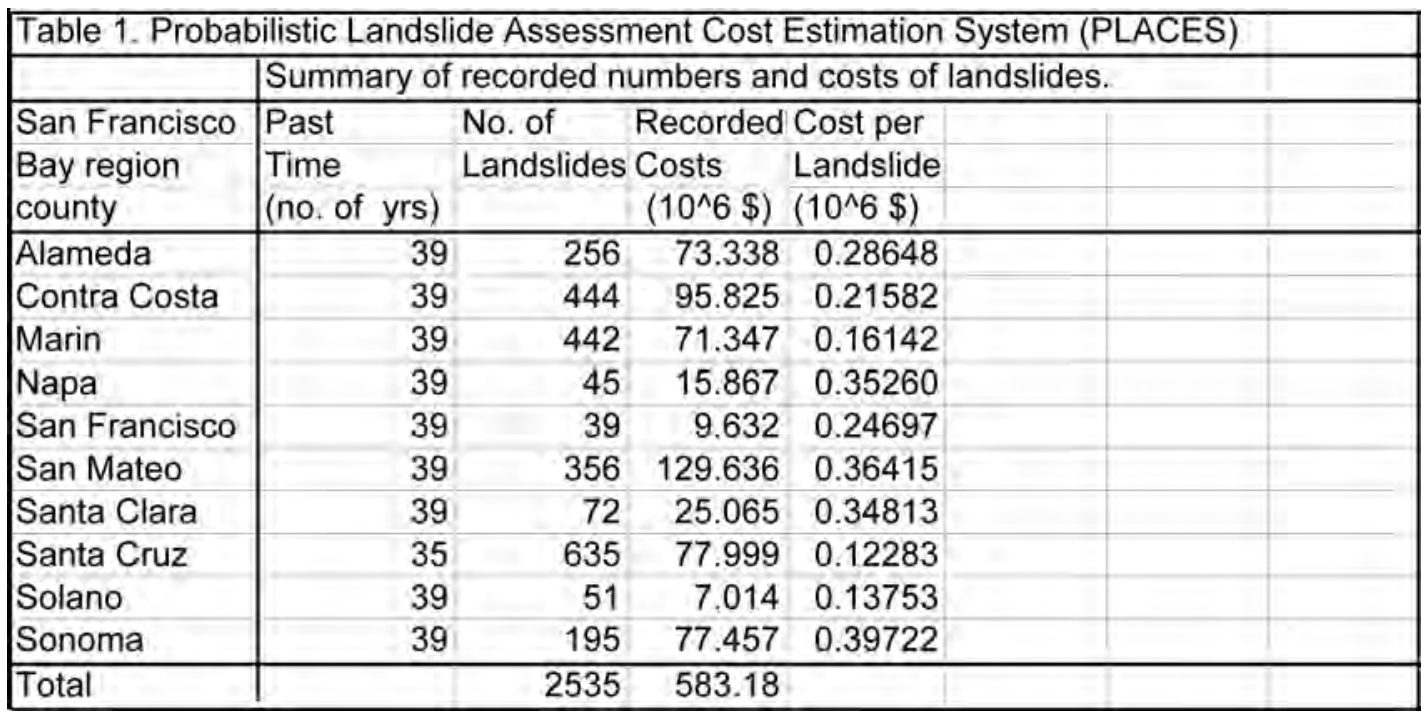


Table 2. Recorded numbers and costs of landslides per landslide cluster. See caption of table 1 for additional information regarding data sources. Designations used in this table: no. of yrs., number of years; S.D., standard deviation.

\begin{tabular}{|c|c|c|c|c|c|c|c|c|c|c|c|c|}
\hline \multirow{3}{*}{$\begin{array}{l}\text { San Francisco } \\
\text { Bay region } \\
\text { county }\end{array}$} & \multirow{2}{*}{\multicolumn{4}{|c|}{ lides per cluster. }} & \multirow{3}{*}{$\begin{array}{l}\text { Sample } \\
8 \text { Mean }\end{array}$} & \multirow{3}{*}{$\begin{array}{l}\text { Sample } \\
\text { S.D. }\end{array}$} & & & & & & \\
\hline & & & & & & & \multicolumn{4}{|c|}{ Cost of landslides per cluster } & \multirow{2}{*}{$\begin{array}{l}\text { Sample } \\
\text { Mean }\end{array}$} & \multirow{2}{*}{$\begin{array}{l}\text { Sample } \\
\text { S.D. }\end{array}$} \\
\hline & $1968-69$ & $1972-73$ & 1982 & $1997-98$ & & & $1968-69$ & $1972-73$ & $\begin{array}{l}1982 \\
\text { (million }\end{array}$ & $\begin{array}{l}1997-98 \\
\text { of } \$ \text { ) }\end{array}$ & & \\
\hline Alameda & 58 & 24 & 87 & 87 & 64.000 & 29.967 & 39.439 & 2.135 & 8.180 & 23.584 & 18.335 & 16.718 \\
\hline Contra Costa & 70 & 110 & 145 & 119 & 111.000 & 31.102 & 37.872 & 10.029 & 16.118 & 31.806 & 23.956 & 13.047 \\
\hline Marin & 86 & 153 & 197 & 26 & 110.500 & 78.335 & 7.710 & 18.215 & 42.430 & 2.992 & 17.837 & 17.587 \\
\hline Napa & 1 & 8 & 20 & 16 & 11.250 & 8.461 & 10.801 & 0.780 & 2.967 & 1.319 & 3.967 & 4.650 \\
\hline San Francisco & 9 & 8 & 17 & 5 & 9.750 & 5.123 & 0.972 & 2.913 & 0.917 & 4.830 & 2.408 & 1.862 \\
\hline San Mateo & 70 & 54 & 191 & 41 & 89.000 & 69.027 & 26.302 & 21.371 & 17.173 & 64,790 & 32.409 & 21.907 \\
\hline Santa Clara & 12 & 16 & 34 & 10 & 18.000 & 10.954 & 13.880 & 0.892 & 1.340 & 8.953 & 6.266 & 6.281 \\
\hline Santa Cruz & & & 470 & 165 & 317.500 & 215.668 & & & 60.706 & 17.293 & 39.000 & 30.698 \\
\hline Solano & 3 & 19 & 23 & 6 & 12.750 & 9.743 & 0.029 & 0.169 & 0.926 & 5.890 & 1.754 & 2.786 \\
\hline Sonoma & 45 & 5 & 138 & 7 & 48.750 & 62.281 & 47.018 & 1.250 & 4.451 & 24.738 & 19.364 & 21.167 \\
\hline Total & 334 & 397 & 1322 & 482 & & & & & & & & \\
\hline
\end{tabular}

Table 3. Numbers and recurrence intervals of landslide clusters. Designations used in this table: Prob., probability; distri., distribution; No., number; yrs., years; S.D., standard deviation; \%, percent.

\begin{tabular}{|c|c|c|c|c|c|c|c|c|}
\hline & & & \multicolumn{3}{|c|}{ Geometric Distri. } & & \multicolumn{2}{|c|}{ Binomial Distri. } \\
\hline San Francisco & No, of & Prob. of & Recurren & ce Interval & Specified & Chance of & No. of $\mathrm{Cl}$ & usters \\
\hline Bay region & Clusters & Cluster & Mean & S.D. & Time & one or more & Mean & S.D. \\
\hline county & & & (no. & of $y r s)$ & (no. of yrs) & clusters (\%) & & \\
\hline Alameda & $\overline{4}$ & 0.103 & 9.750 & 9.236 & 5 & 41.787 & 0.513 & 0.678 \\
\hline Contra Costa & 4 & 0.103 & 9.750 & 9.236 & 5 & 41.787 & 0.513 & 0.678 \\
\hline Marin & 4 & 0.103 & 9.750 & 9.236 & 5 & 41.787 & 0.513 & 0.678 \\
\hline Napa & 4 & 0.103 & 9.750 & 9.236 & 5 & 41.787 & 0.513 & 0.678 \\
\hline San Francisco & 4 & 0.103 & 9.750 & 9.236 & 5 & 41.787 & 0.513 & 0.678 \\
\hline San Mateo & 4 & 0.103 & 9.750 & 9.236 & 5 & 41.787 & 0.513 & 0.678 \\
\hline Santa Clara & 4 & 0.103 & 9.750 & 9.236 & 5 & 41.787 & 0.513 & 0.678 \\
\hline Santa Cruz & 2 & 0.057 & 17.500 & 16.993 & 5 & 25.487 & 0.286 & 0.519 \\
\hline Solano & 4 & 0.103 & 9.750 & 9.236 & 5 & 41.787 & 0.513 & 0.678 \\
\hline Sonoma & 4 & 0.103 & 9.750 & 9.236 & 5 & 41.787 & 0.513 & 0.678 \\
\hline
\end{tabular}


Table 4. Future total numbers of landslides and their aggregation. The three aggregations assume respectively perfect positive correlation (p.p.c.), independence (indep.), and weighted-average correlation coefficient of 0.5 for illustrative purposes. Designations used in this table: No., number; S.D., standard deviation; \%, percent; Aggre., Aggregation.

\begin{tabular}{|c|c|c|c|c|c|c|c|c|c|c|}
\hline \multirow{3}{*}{$\begin{array}{l}\text { San Francisco } \\
\text { Bay region } \\
\text { county }\end{array}$} & \multicolumn{10}{|c|}{ Estimates of number of landslides during a specified time. } \\
\hline & \multicolumn{2}{|c|}{ No. of Landslides } & \multicolumn{2}{|c|}{ Lognormal } & \multirow{2}{*}{$\begin{array}{l}\text { Prediction } \\
\text { Level } \\
\text { (\%) }\end{array}$} & \multicolumn{3}{|c|}{ No. of Landslides } & \multirow{2}{*}{$\begin{array}{l}\text { Specified } \\
\text { No. (SN) }\end{array}$} & \multirow{2}{*}{$\begin{array}{l}\text { Chance } \\
\text { Exceed } \\
\text { SN (\%) }\end{array}$} \\
\hline & Mean & S.D. & Mu & Sigma & & Low & & High & & \\
\hline Alameda & 32.821 & 48.431 & 2.913 & 1.075 & 90 & & 3 & 108 & 10 & 71.489 \\
\hline Contra Costa & 56.923 & 78.527 & 3.509 & 1.032 & 90 & & 6 & 183 & 10 & 87.868 \\
\hline Marin & 56.667 & 93.628 & 3.379 & 1.147 & 90 & & 4 & 194 & 10 & 82.592 \\
\hline Napa & 5.769 & 9.745 & 1.078 & 1.161 & 90 & & 0 & 20 & 10 & 14.587 \\
\hline San Francisco & 5.000 & 7.564 & 1.014 & 1.091 & 90 & & 0 & 17 & 10 & 11.884 \\
\hline San Mateo & 45.641 & 78.031 & 3.137 & 1.169 & 90 & & 3 & 158 & 10 & 76.240 \\
\hline Santa Clara & 9.231 & 14.514 & 1.600 & 1.116 & 90 & & 1 & 31 & 10 & 26.448 \\
\hline Santa Cruz & 90.714 & 201.110 & 3.619 & 1.333 & 90 & & 4 & 334 & 10 & 83.827 \\
\hline Solano & 6.538 & 11.113 & 1.199 & 1.165 & 90 & & 0 & 23 & 10 & 17.175 \\
\hline Sonoma & 25.000 & 55.524 & 2.329 & 1.334 & 90 & & 1 & 92 & 10 & 50.779 \\
\hline Aggre. (p.p.c.) & 334.304 & 598.187 & 5.094 & 1.198 & 90 & & 22 & 1160 & 100 & 65.845 \\
\hline Aggre. (indep.) & 334.304 & 259.580 & 5.576 & 0.687 & 90 & & 85 & 817 & 100 & 92.125 \\
\hline 0.5 & 334.304 & 461.091 & 5.279 & 1.032 & 90 & & 36 & 1072 & 100 & 74.314 \\
\hline
\end{tabular}

Table 5. Future total costs of landslides and their aggregation. The three aggregations assume respectively perfect positive correlation (p.p.c.), independence (indep.), and weighted-average correlation coefficient of 0.5 for illustrative purposes. Designations used in this table: S.D., standard deviation; \%, percent; Aggre., Aggregation; $10^{\wedge} 6 \$$, million dollars.

\begin{tabular}{|c|c|c|c|c|c|c|c|c|c|}
\hline \multirow{4}{*}{$\begin{array}{l}\text { San Francisco } \\
\text { Bay region } \\
\text { county }\end{array}$} & \multicolumn{9}{|c|}{ Estimates of total damage as economic loss during a specified time. } \\
\hline & \multicolumn{2}{|c|}{ Total Costs } & \multicolumn{2}{|c|}{ Lognormal } & \multirow{3}{*}{$\begin{array}{l}\text { Prediction } \\
\text { Level } \\
(\%)\end{array}$} & \multicolumn{2}{|c|}{ Total Costs } & \multirow{3}{*}{$\begin{array}{l}\text { Specified } \\
\text { Costs (SC) } \\
\left(10^{\wedge} 6 \$\right)\end{array}$} & \multirow{3}{*}{$\begin{array}{l}\text { Chance } \\
\text { Exceed } \\
\text { SC (\%) }\end{array}$} \\
\hline & Mean & S. D. & Mu & Sigma & & Low & High & & \\
\hline & (millio & ns of \$) & & & & (millic & ns of \$) & & \\
\hline Alameda & 9.40231 & 17.26379 & 1.503 & 1.215 & 90 & 0.61000 & 33.15308 & 25 & 7.891 \\
\hline ontra & 12.28526 & 18.74614 & 1.907 & 1.097 & 90 & 0898 & & 2 & 581 \\
\hline Marin & 9.14705 & 17.46521 & 1.445 & 1.239 & 90 & 263 & & 25 & .622 \\
\hline apa & 2.03423 & 4.28147 & -0.136 & 1.301 & 90 & 0.10276 & & 25 & 0.495 \\
\hline in Francisco & 1.23487 & 2.10890 & -0.472 & 1.1 & 90 & 131 & & 25 & 0.079 \\
\hline San Mateo & 16.62000 & 27.00948 & 2.164 & 1.1 & 90 & 4265 & & 25 & 17.682 \\
\hline Clara & 3.21346 & 6.18869 & 0.393 & 1.2 & 9 & 112 & & 2 & 159 \\
\hline Santa Cruz & 11.14271 & 26.05704 & 1.477 & 1.366 & 90 & 0.46294 & 06 & 25 & 10.123 \\
\hline Solano & 0.89923 & 2.32262 & -1.125 & 1.427 & 90 & 0,03103 & & 25 & 0.117 \\
\hline Sonoma & 9.93038 & 20.05839 & 1.483 & 1.275 & 90 & 0.54116 & 35.87101 & 25 & 8.665 \\
\hline Aggre (p.p.c.) & 75.90951 & 141.50172 & 3.580 & 1.224 & 90 & 5.03458 & 267.02005 & 100 & 20.123 \\
\hline Aggre. (indep.) & 75.90951 & 53.21450 & 4.130 & 0.632 & 90 & 21.97078 & 175 & 100 & 22.600 \\
\hline 0.5 & 75.90951 & 106.89836 & 3.783 & 1.045 & 90 & 7.87301 & 245.34682 & 100 & 21.583 \\
\hline
\end{tabular}


Table 6. Recorded percentages of public and private costs. See title of table 1 for additional information regarding data sources. Designations used in this table: \%, percent; $10^{\wedge} 6 \$$, million dollars.

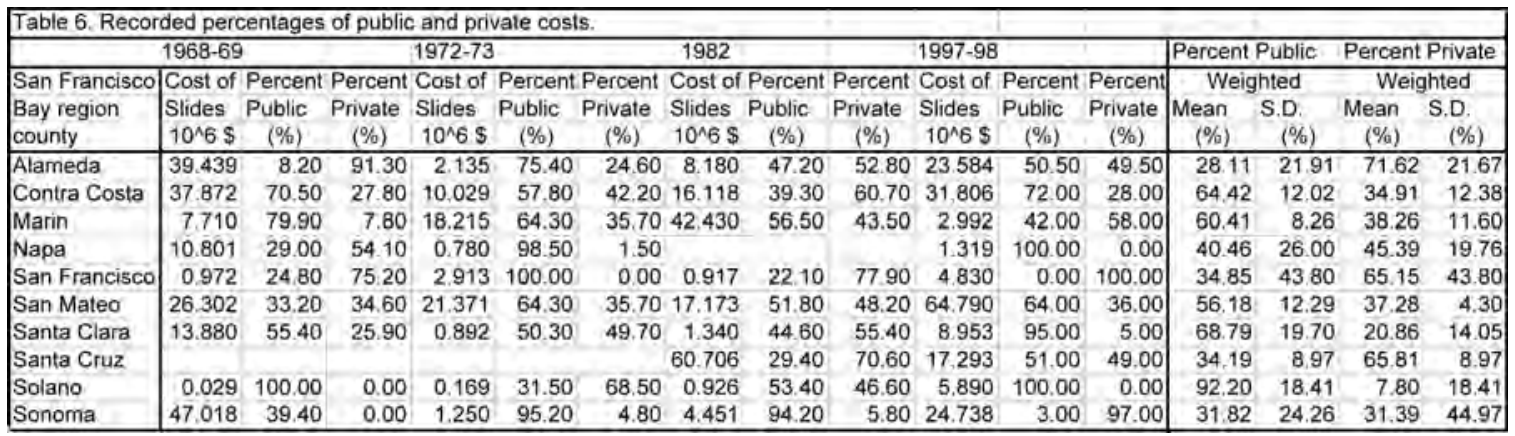

Table 7. Future public costs of landslides and their aggregation. The three aggregations assume respectively perfect positive correlation (p.p.c.), independence (indep.), and weighted-average correlation coefficient of 0.5 for illustrative purposes. Designations used in this table: S.D., standard deviation; \%, percent; Aggre., Aggregation; $10^{\wedge} 6 \$$, million dollars.

\begin{tabular}{|c|c|c|c|c|c|c|c|c|c|}
\hline \multirow{4}{*}{$\begin{array}{l}\text { San Francisco } \\
\text { Bay region } \\
\text { county }\end{array}$} & \multicolumn{9}{|c|}{ Estimates of public damage as economic loss during a specified time. } \\
\hline & \multicolumn{2}{|c|}{ Public Costs } & \multicolumn{2}{|c|}{ Lognormal } & \multirow{3}{*}{$\begin{array}{l}\text { Prediction } \\
\text { Level } \\
\text { (\%) }\end{array}$} & \multicolumn{2}{|c|}{ Public Costs } & \multirow{3}{*}{$\begin{array}{c}\text { Specified } \\
\text { Costs (SC) } \\
\left(10^{\wedge} 6 \$\right)\end{array}$} & \multirow{3}{*}{$\begin{array}{l}\text { Chance } \\
\text { Exceed } \\
\text { SC (\%) }\end{array}$} \\
\hline & Mean & S. D. & $\mathrm{Mu}$ & Sigma & & Low & High & & \\
\hline & (million & is of \$) & & & & (millio & ns of \$) & & \\
\hline Alameda & 2.643 & 6.489 & -0.003 & 1.396 & 90 & 0.10027 & 9.91233 & 10 & 4.935 \\
\hline Contra Costa & 7.914 & 12.373 & 1.450 & 1.112 & 90 & 0.68464 & 26.56267 & 10 & 22.173 \\
\hline Marin & 5.526 & 10.676 & 0.932 & 1.247 & 90 & 0.32675 & 19.74678 & 10 & 13.586 \\
\hline Vapa & 0.823 & 2.126 & -1.213 & 1.427 & 90 & 0.02840 & 3.10946 & 10 & 0.689 \\
\hline San Francisco & 0.430 & 1.298 & -2.000 & 1.521 & 90 & 0.01110 & 188 & 10 & 0.234 \\
\hline San $M$ & 9.338 & 15.668 & 1.565 & 1.157 & 90 & 0.71262 & 32.07 & 10 & 26.181 \\
\hline Santa Clara & 2.210 & 4.473 & -0.021 & 1.276 & 90 & 0.12005 & 7.98800 & 10 & 3.431 \\
\hline Santa Cruz & 3.810 & 9.264 & 0.371 & 1.391 & 90 & 0.14713 & 14.26 & 10 & 8.237 \\
\hline Solano & 0.829 & 2.190 & -1.226 & 1.441 & 90 & 0.02743 & 3.14101 & 10 & 0.717 \\
\hline Sonoma & 3.160 & 8.381 & 0.109 & 1.443 & 90 & 0.10380 & 11.97883 & 10 & 6.429 \\
\hline Aggre. (p.p.c.) & 36.684 & 72.938 & 2.802 & 1.265 & $\overline{90}$ & 2.26218 & 130.42799 & 50 & 19.016 \\
\hline Aggre. (indep.) & 36.684 & 27.235 & 3.383 & 0.663 & 90 & 9.90424 & 87.59104 & 50 & 21.223 \\
\hline 0.5 & 36.684 & 55.053 & 3.013 & 1.086 & 90 & 3.40886 & 121.38080 & 50 & 20.379 \\
\hline
\end{tabular}


Table 8. Future private costs of landslides and their aggregation. The three aggregations assume respectively perfect positive correlation (p.p.c.), independence (indep.), and weighted-average correlation coefficient of 0.5 for illustrative purposes. Designations used in this table: S.D., standard deviation; \%, percent; Aggre., Aggregation; $10^{\wedge} 6 \$$, million dollars.

Table 8. Future private costs of landslides and their aggregation.

\begin{tabular}{|c|c|c|c|c|c|c|c|c|c|}
\hline \multirow{3}{*}{\begin{tabular}{|l|} 
\\
San Francisco \\
Bay region \\
county
\end{tabular}} & \multicolumn{9}{|c|}{ Estimates of private damage as economic loss during a specified time. } \\
\hline & \multicolumn{2}{|c|}{ Private Costs } & \multicolumn{2}{|c|}{ Lognormal } & \multirow{2}{*}{$\begin{array}{l}\text { Prediction } \\
\text { Level } \\
\text { (\%) }\end{array}$} & \multicolumn{2}{|c|}{ Private Costs } & \multirow{2}{*}{$\begin{array}{l}\text { Specified } \\
\text { Costs (SC) } \\
\left(10^{\wedge} 6 \$\right)\end{array}$} & \multirow{2}{*}{$\begin{array}{l}\text { Chance } \\
\text { Exceed } \\
\text { SC (\%) }\end{array}$} \\
\hline & $\begin{array}{l}\text { Mean } \\
\text { (million }\end{array}$ & $\begin{array}{l}\text { S. D. } \\
\text { ns of } \$ \text { ) }\end{array}$ & $\mathrm{Mu}$ & Sigma & & Low & High & & \\
\hline Alameda & 6.734 & 13.078 & 1.126 & 1.250 & 90 & 0.39444 & 24.09555 & 10 & 17.327 \\
\hline Contra Costa & 4.288 & 7.108 & 0.795 & 1.149 & 90 & 0.33453 & 14.67181 & 10 & 9.488 \\
\hline Marin & 3.500 & 7.063 & 0.441 & 1.274 & 90 & 0.19101 & 12.63872 & 10 & 7.200 \\
\hline Napa & 0.923 & 2,157 & -1.013 & 1.366 & 90 & 0.03842 & 3.43509 & 10 & 0.761 \\
\hline San Francisco & 0.805 & 1.742 & -1.087 & 1.318 & 90 & 0.03858 & 2.95050 & 10 & 0.507 \\
\hline San Mateo & 6.196 & 10.162 & 1.171 & 1.143 & 90 & 0.49256 & 21.12787 & 10 & 16.104 \\
\hline Santa Clara & 0.670 & 1.620 & -1.362 & 1.387 & 90 & 0.02618 & 2.50790 & 10 & 0.412 \\
\hline Santa Cruz & 7.333 & 17.336 & 1.050 & 1.373 & 90 & 0.29856 & 27.33716 & 10 & 18.077 \\
\hline Solano & 0.070 & 0.493 & -4.617 & 1.980 & 90 & 0.00038 & 0.25660 & 10 & 0.024 \\
\hline Sonoma & 3.117 & 11.872 & -0.234 & 1.656 & 90 & 0.05198 & 12.05697 & 10 & 6.278 \\
\hline Aggre. (p.p.c.) & 33.637 & 72.630 & 2.649 & 1.317 & 90 & 1.86662 & 121.07818 & 50 & 16.868 \\
\hline Aggre. (indep.) & 33.637 & 28.753 & 3.241 & 0.741 & 90 & 7.56231 & 86.45081 & 50 & 18.259 \\
\hline 0.5 & 33.637 & 55.235 & 2.862 & 1.143 & 90 & 2.66769 & 114.74080 & 50 & 17.921 \\
\hline
\end{tabular}

